\title{
The cranberry flavonoids PAC DP-9 and quercetin aglycone induce cytotoxicity and cell cycle arrest and increase cisplatin sensitivity in ovarian cancer cells
}

\author{
YIFEI WANG ${ }^{1}$, ALEX HAN ${ }^{2}$, EVA CHEN $^{2}$, RAKESH K. SINGH ${ }^{2}$, CLINTON O. CHICHESTER $^{3}$, \\ RICHARD G. MOORE ${ }^{2}$, AJAY P. SINGH ${ }^{1}$ and NICHOLI VORSA ${ }^{1,4}$ \\ ${ }^{1}$ Department of Plant Biology and Pathology, Rutgers University, New Brunswick, NJ 08901; \\ ${ }^{2}$ Molecular Therapeutics Laboratory, Program in Women's Oncology, \\ Women and Infants' Hospital of Rhode Island, Alpert Medical School, Brown University, \\ Providence, RI 02905; ${ }^{3}$ College of Pharmacy, University of Rhode Island, Kingston, RI 02881; \\ ${ }^{4}$ Philip E. Marucci Center for Blueberry and Cranberry Research and Extension, \\ Rutgers University, Chatsworth, NJ 08019, USA
}

Received December 9, 2014; Accepted January 30, 2015

DOI: $10.3892 /$ ijo.2015.2931

\begin{abstract}
Cranberry flavonoids (flavonols and flavan-3-ols), in addition to their antioxidant properties, have been shown to possess potential in vitro activity against several cancers. However, the difficulty of isolating cranberry compounds has largely limited anticancer research to crude fractions without well-defined compound composition. In this study, individual cranberry flavonoids were isolated to the highest purity achieved so far using gravity and high performance column chromatography and LC-MS characterization. MTS assay indicated differential cell viability reduction of SKOV-3 and OVCAR-8 ovarian cancer cells treated with individual cranberry flavonoids. Treatment with quercetin aglycone and PAC DP-9, which exhibited the strongest activity, induced apoptosis, led to caspase- 3 activation and PARP deactivation, and increased sensitivity to cisplatin. Furthermore, immunofluorescence microscopy and western blot study revealed reduced expression and activation of epidermal growth factor receptor (EGFR) in PAC DP-9 treated SKOV-3 cells. In addition, quercetin aglycone and PAC DP-9 deactivated MAPK-ERK pathway, induced downregulation of cyclin D1, DNA-PK, phospho-histone $\mathrm{H} 3$ and upregulation of p21, and arrested cell cycle progression. Overall, this study demonstrates promising in vitro cytotoxic and anti-proliferative properties of two newly characterized cranberry flavonoids, quercetin aglycone and PAC DP-9, against ovarian cancer cells.
\end{abstract}

Correspondence to: Dr Nicholi Vorsa, Department of Plant Biology and Pathology, Rutgers University, 59 Dudley Road, New Brunswick, NJ 08901, USA

E-mail: vorsa@aesop.rutgers.edu

Key words: cranberry, flavonoids, ovarian cancer, apoptosis, cell cycle

\section{Introduction}

Epithelial ovarian cancer (EOC) is an asymptotic lethal disease that is frequently diagnosed at late stages in women (1). Initial responsiveness to chemotherapy and surgery is often thwarted by inherent or acquired resistance, resulting in early recurrence and premature death (2). Approximately 22,000 women will be diagnosed with EOC this year in the US alone, and more than 14,000 will succumb to their disease (3). Because firstline platinum-taxane and second-line dox-topotecan therapies often fail, third-line chemotherapy options are urgently needed.

American cranberry (Vaccinium macrocarpon) has received attention in our laboratories and elsewhere because of the potential for cranberry A-type proanthocyanidins (PACs) and flavonols to treat upper urinary tract infections and cancer (4-6). However, the isolation of pure PACs and flavonol constituents has remained an unmet challenge that frequently impedes broad-spectrum screening for biological activity. Semi-pure cranberry PACs have consistently exhibited potent anti-proliferative activity against various cancer cells in vitro (6-8). We had previously developed an iterative but efficient HPLC and mass spectrometry-based approach to generate high-purity polymeric PAC fractions from cranberries (9). Purified PACs have exhibited cytotoxic effects against a panel of gynecologic cancer and neuroblastoma cells in our laboratories (9-11). PACs exerted these cytotoxic effects via cell cycle arrest, production of lethal levels of intracellular reactive oxygen species (ROS), and induction of pro-apoptotic signal transductions at low microgram concentrations $(10,11)$. Further optimization of the purification and a detailed investigation of the mechanism of anti-proliferative action have been pursued in our laboratories since purified PACs became accessible.

In this study, we further elaborate analytical methodology to isolate and purify individual flavonols and PACs of cranberry for broad-spectrum biological activity screening studies. We also describe the two most active leads, PAC DP-9 and quercetin aglycone, in SKOV-3 and OVCAR-8 ovarian cancer 
cells, and we characterize their anti-proliferative efficacy and mechanism of cell cycle arrest, induction of apoptotic activities, and inhibition of oncogenes and DNA repair machinery. The multifaceted anti-proliferative properties exerted by these two cranberry flavonoids highlight their potential for treatment of ovarian cancer.

\section{Materials and methods}

Plant material. Cranberry fruits of cultivar 'Stevens' were harvested from the Philip E. Marucci Center for Blueberry and Cranberry Research and Extension and kept frozen at $-20^{\circ} \mathrm{C}$ before use.

Reagents and LC-MS instrumentation. All solvents were purchased from EMD Millipore (Billercia, MA, USA). Sephadex ${ }^{\circledR}$ LH-20 was obtained from GE Healthcare Bio-Science (Piscataway, NJ, USA), and BakerBound ${ }^{\circledR}$ Diol was obtained from Avantor Performance Materials (Center Valley, PA, USA). LC-MS spectra were obtained with a Dionex UltiMate ${ }^{\circledR} 3000$ LC system (Thermal Scientific, Sunnyvale, CA, USA) including the UltiMate 3000 RS Pump, UltiMate 3000 RS Autosampler, UltiMate 3000 RS Column Compartment and UltiMate 3000 RS Diode Array Detector coupled with Applied Biosystems API $3000^{\mathrm{TM}}$ triple quad LC-MS/MS mass spectrometer (AB SCIEX, Framingham, MA, USA). Previously described HPLC methods for flavonol and PAC identification $(12,13)$ were modified slightly for LC-MS analysis. Structure and purity of flavonols and PACs were determined by HPLC-PDA/Fluorescence and/or LC-MS.

Extraction and isolation of individual cranberry flavonols and PACs. Crude flavonoids were extracted and further separated in a Sephadex LH-20 column as previously described (14). Individual cranberry flavonols were isolated using a semi-preparative HPLC system as described previously (14). Individual PACs were isolated with a regular Diol gravity column chromatography as previously reported (9). Eight flavonols were isolated and characterized as myricetin3-galactoside, quercetin-3-galactoside, quercetin-3-glucoside, quercetin-3-xylopyranoside, quercetin-3-arabinopyranosdie, quercetin-3-arabinofuranoside, quercetin-3-rhamnopyranoside and quercetin aglycone. Eleven cranberry A-type PACs from dimer to polymer 12 (named as PAC DP-2 to PAC DP-12) were isolated and characterized. Purity of all isolated cranberry flavonoids was $>95 \%$ (w/w) based on HPLC and LC-MS analysis.

Cell lines and cell culture. SKOV-3 and OVCAR-8 cells (ovarian epithelial adenocarcinoma) were purchased from ATCC (Manassas, VA, USA). Cells were cultured with Dulbecco's modified Eagle's medium (DMEM, Life Technologies, Carlsbad, CA, USA) supplemented with $10 \%$ fetal bovine serum (Life Technologies), $100 \mu \mathrm{g} / \mathrm{ml}$ streptomycin and $100 \mu \mathrm{g} / \mathrm{ml}$ penicillin (Life Technologies) in an incubator at $37^{\circ} \mathrm{C}, 5 \% \mathrm{CO}_{2}$ and $95 \%$ humidity. For all assays, cells were allowed to attach for $24 \mathrm{~h}$ prior to treatment.

Cell viability assay. Cells (5,000/well) were seeded in 96-well flat bottom plates (USA Scientific, Orlando, FL, USA) and treated with various concentrations of flavonoids for $72 \mathrm{~h}$.
Cell viability was determined by CellTiter $96^{\circledR}$ Aqueous One Solution assay (Promega, Madison, WI, USA) following the manufacturer's protocol. Experiments were performed in triplicate; data are expressed as mean of triplicate measurements (mean \pm SD) in percentage of untreated cells (100\%). SPSS Statistics 19 (IBM Corp., Armonk, NY, USA) was used to perform ANOVA with linear regression between cell viability and compound concentration, calculate $\mathrm{IC}_{50}$ value of each cranberry flavonoid, and conduct Student's t-tests and calculate p-values based on mean cell viability for each treatment.

DNA fragmentation analysis. DNA fragmentation as a hallmark of apoptosis was studied using the Roche In Situ Cell Death Detection kit (Branford, CT, USA) (TUNEL assay). SKOV-3 and OVCAR- 8 cells $\left(2 \times 10^{4} /\right.$ well) were seeded in Lab-Tek 8 -well chamber glass slides (Nalge Nunc., Naperville, IL, USA) and treated with $50 \mu \mathrm{g} / \mathrm{ml}$ PAC DP-9, $25 \mu \mathrm{g} / \mathrm{ml}$ quercetin aglycone, or DMSO vehicle control for $12 \mathrm{~h}$. Cells were fixed with $10 \%$ neutral buffered formalin, and stained according to the manufacturer's protocol. Slides were then cover-slipped with Vectashield mounting medium with DAPI (Vector Laboratories, Burlingame, CA, USA). Images were acquired on a Nikon E800 upright microscope (Nikon Instruments, Inc., Melville, NY, USA) using SPOT Advanced Software (SPOT Imaging Solutions, Sterling Heights, MA, USA).

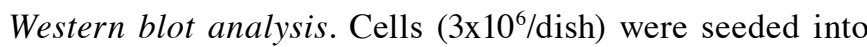
$100-\mathrm{mm}^{2}$ tissue culture dishes and treated with individual cranberry flavonoids. Cells were then lysed with cell lysis buffer (Cell Signaling Technology, Inc., Danvers, MA, USA) supplemented with $5 \mu \mathrm{l} / \mathrm{ml}$ phenylmethylsulfonyl fluoride (Sigma-Aldrich, St. Louis, MO, USA). Protein concentrations of cell lysates were determined with Pierce BCA protein assay kit (Pierce Technology, Rockford, IL, USA). Gel electrophoresis was performed in NuPAGE Gel system (Life Technologies) according to the manufacturer's instructions. Separated proteins were transferred onto a nitrocellulose membrane, which was then blocked with 5\% non-fat milk in PBS-Tween buffer and probed against various primary antibodies (cleaved caspase-3 no. 9664, cleaved PARP no. 5625, EGFR no. 4267, phosphoEGFR no. 3777, phospho-c-Raf no. 9427, phospho-ERK1/2 no. 4370, phospho-p53 no. 9286, p18 INK4C no. 2896, p21 Waf1/ Cip1 no. 2947, p27 Kip1 no. 3686, CDK2 no. 2546, cyclin D1 no. 2926 , cyclin D3 no. 2936 , $\beta$-actin no. 8457 , $\beta$-tubulin no. 2128; Cell Signaling Technology). Protein bands were visualized using horseradish peroxidase conjugated anti-rabbit or anti-mouse secondary antibody (Cell Signaling Technology) and Pierce ECL Western Blotting Substrate, and documented by Bio-Rad Gel Doc system (Bio-Rad, Hercules, CA, USA).

Immunofluorescence microscopy analysis. SKOV-3 and OVCAR-8 cells $\left(2 \times 10^{4} /\right.$ well) were seeded in Lab-Tek 8 -well chamber slides and treated with individual cranberry flavonoids overnight for $12 \mathrm{~h}$. Cells were fixed with $10 \%$ neutral buffered formalin, washed 3 times with PBS-Tween $0.1 \%$ and blocked with 5\% horse serum (Vector Laboratories) in PBS-Tween for 30 min. Blocked cells were incubated with various primary antibodies (EGFR no. 4267, p21 Waf1/Cip1 no. 2947, phosphoERK1/2 no. 4370,DNA-PK no.4602, Cell Signaling Technology; and MEK no. sc-166197, phospho-histone H3 no. sc-12927, 
A

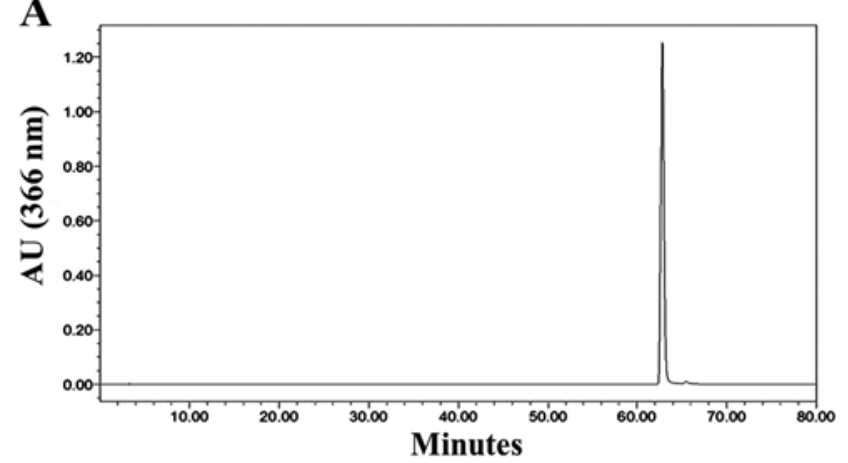

C

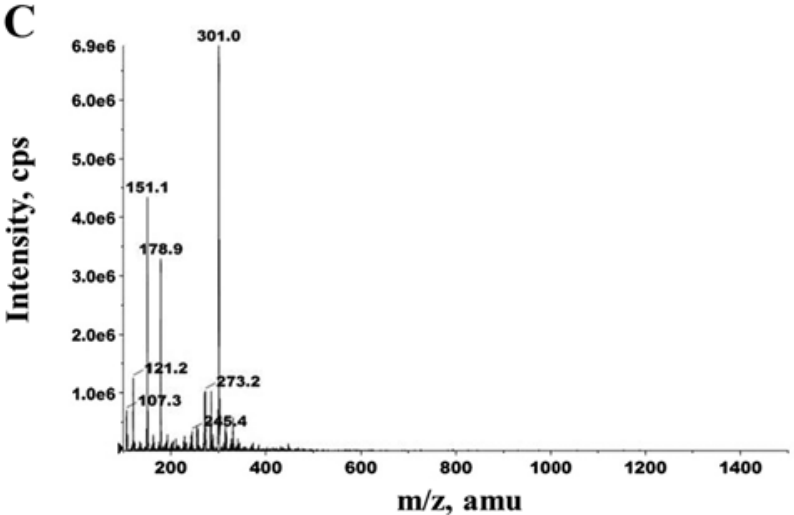

B

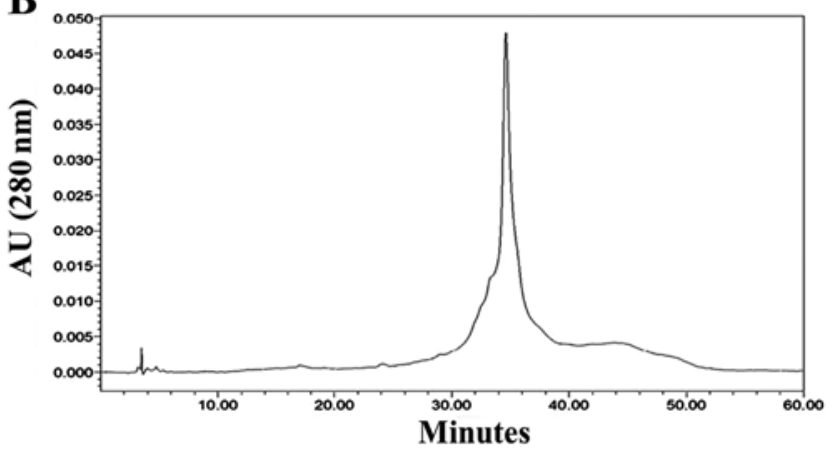

D<smiles>O=c1cc(C2C=CC(O)=C(O)C2)oc2cc(O)cc(O)c12</smiles>

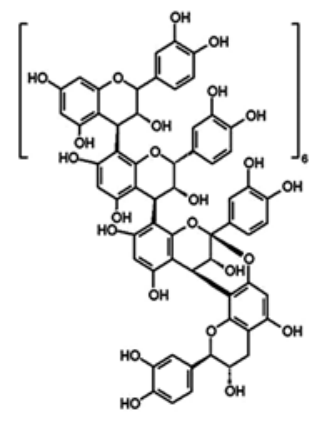

PAC DP-9

Figure 1. Structures of cranberry flavonoids quercetin aglycone and PAC DP-9. (A) HPLC chromatograph of quercetin aglycone; (B) HPLC chromatograph of PAC DP-9; (C) MS spectrum of quercetin aglycone (m/z=301); (D) Structures of quercetin algycone and PAC DP-9.

cyclin D1 no. sc-246, Santa Cruz Biotechnology, Dallas, TX, USA) at $4^{\circ} \mathrm{C}$ overnight. Probed proteins were visualized with DyLight 488/594 (Thermo Scientific, Waltham, MA, USA) or Alexa Fluor ${ }^{\circledR} 594$ (Cell Signaling Technology) secondary antibodies, and nuclei were stained with Vectorshield ${ }^{\circledR}$ mounting medium with DAPI (Vector Laboratories). Images were acquired on Olympus FSX100 ${ }^{\circledR}$ (Olympus America Inc., Center Valley, PA, USA; for EGFR) or Nikon E800 upright (for other proteins) microscope system.

Co-immunoprecipitation analysis. SKOV-3 and OVCAR-8 cells were cultured in $100 \mathrm{~mm}^{2}$ tissue culture dishes to $80 \%$ confluency. Cells were lysed and protein concentration was quantified as described earlier. Lysate containing $500 \mu \mathrm{g}$ protein was incubated with target antibody or control IgG antibody (Cell Signaling Technology) for $4 \mathrm{~h}$ with rotation at $4^{\circ} \mathrm{C}$. Protein G sepharose (75 $\mu$ l) (50\% slurry, GE Healthcare Life Sciences) was added to the lysate and incubated at $4^{\circ} \mathrm{C}$ overnight. After incubation, beads were washed with $500 \mu 1$ lysis buffer 3 times and re-suspended in $40 \mu 1$ Laemmli buffer (2X, Bio-Rad), vortexed, and heated to $95^{\circ} \mathrm{C}$ for $5 \mathrm{~min}$. Suspension was centrifuged to collect supernatant for western blot analysis.

Cell cycle analysis. SKOV-3 and OVCAR- 8 cells ( $3 \times 10^{5} /$ well) were seeded in 6-well plates and treated with a series of concentrations of individual cranberry flavonoids $(0-100 \mu \mathrm{g} / \mathrm{ml}$, 24-48 h). After trypsinization, cells were collected and fixed in ice-cold $70 \%$ ethanol and stained with solution containing propidium iodide (Sigma-Aldrich; $0.1 \mathrm{mg} / \mathrm{ml}$ ), sodium citrate (Sigma-Aldrich; $2 \mathrm{mg} / \mathrm{ml}$ ) and Triton X-100 (Sigma-Aldrich;
$1 \mu \mathrm{l} / \mathrm{ml})$. Cell counting data were acquired in an Accuri ${ }^{\circledR} \mathrm{C} 6$ Flow Cytometer (BD Biosciences, San Jose, CA, USA) and analyzed with ModFit LT software (Verity Software House, Inc., Topsham, ME, USA).

\section{Results}

Individual cranberry flavonoids display differential cytotoxicity against ovarian cancer cell lines. Individual cranberry flavonols and PACs exhibited different levels of cytotoxicity against SKOV-3 and OVCAR-8 cell-lines (Fig. 2). Quercetin-3xylopyranoside did not show cytotoxicity against SKOV-3 and OVCAR- 8 cells, while myricetin-3-galactoside and quercetin3 -arabinopyranoside were cytotoxic to OVCAR- 8 cells $\left(\mathrm{IC}_{50}\right.$, 130 and $212 \mu \mathrm{g} / \mathrm{ml}$ ) but non-toxic to SKOV-3 cells at treatment concentrations. Compared to quercetin glycosides, quercetin aglycone exhibited higher cytotoxicity against the two cancer cell lines ( $\mathrm{IC}_{50}, 83$ and $61 \mu \mathrm{g} / \mathrm{ml}$ for SKOV-3 and OVCAR-8 cells, respectively).

Cranberry PAC DP-3, DP-7, and DP-10 exhibited less cytotoxicity against both SKOV-3 and OVCAR-8 cells than other PACs. PAC DP-5 and DP-12 were more effective against SKOV-3 cells $\left(\mathrm{IC}_{50}, 126 \mu \mathrm{g} / \mathrm{ml}\right.$ and $162 \mu \mathrm{g} / \mathrm{ml}$ for DP-5 and DP-12, respectively) than OVCAR-8 cells. Compared to other cytotoxic PAC molecules, PAC DP-9 exhibited the highest activity against SKOV-3 cells $\left(\mathrm{IC}_{50}, 82 \mu \mathrm{g} / \mathrm{ml}\right)$ and relatively high cytotoxicity against OVCAR-8 cells $\left(\mathrm{IC}_{50}, 138 \mu \mathrm{g} / \mathrm{ml}\right)$. Based on these results, quercetin aglycone and PAC DP-9 (Fig. 1) were selected as lead candidates for our studies in 

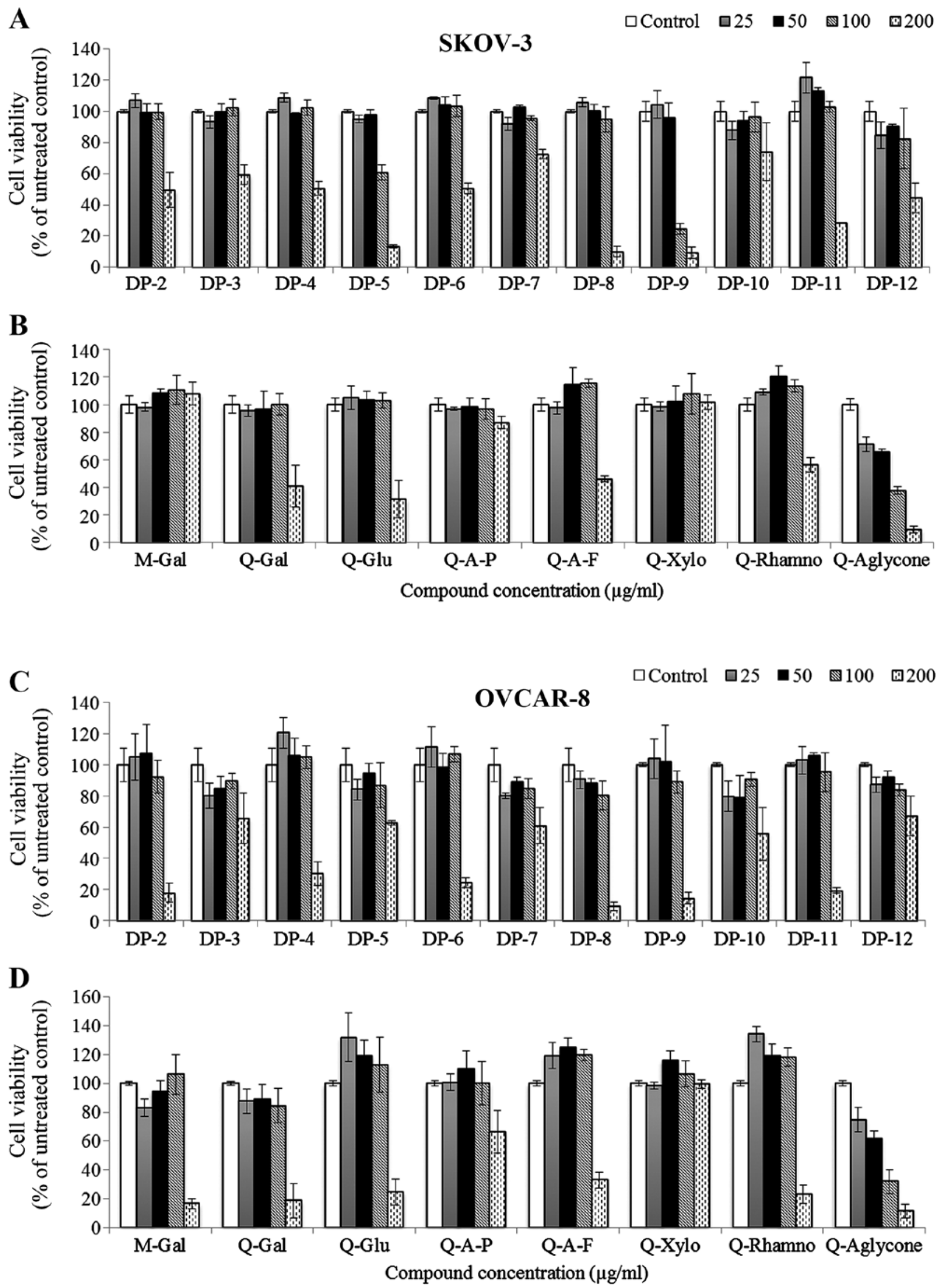

Figure 2. Cytotoxicity of individual cranberry flavonols and PACs in SKOV-3 and OVCAR-8 ovarian cancer cells. Cytotoxicity was determined by MTS cell viability assay; cells were treated with DMSO vehicle or different concentrations of cranberry flavonoids $(25-200 \mu \mathrm{g} / \mathrm{ml})$ for $72 \mathrm{~h}$. Experiments were performed in triplicate; data are expressed as mean \pm SD in percent of cell viability of untreated cells (100\%). M-Gal, myricetin-3-galactoside; Q-Gal, quercetin-3-galactoside; Q-Glu, quercetin-3-glucoside; Q-A-P, quercetin-3-arabinopyranoside; Q-A-F, quercetin-3-arabinofuranoside; Q-Xylo, quercetin3-xylopyranoside; Q-Rhamno, quercetin-3-rhamnopyranoside;Q-Aglycone, quercetin aglycone. 
Table I. Correlation coefficient (r), p-value and $\mathrm{IC}_{50}$ value of individual cranberry PACs and flavonols against SKOV-3 and OVCAR-8 cells. ${ }^{\text {a }}$

\begin{tabular}{|c|c|c|c|c|c|c|}
\hline \multirow[b]{2}{*}{ Compound } & \multicolumn{3}{|c|}{ SKOV-3 } & \multicolumn{3}{|c|}{ OVCAR-8 } \\
\hline & Correlation coefficient & $\mathrm{p}$-value & $\mathrm{IC}_{50}(\mu \mathrm{g} / \mathrm{ml})$ & Correlation coefficient & $\mathrm{p}$-value & $\mathrm{IC}_{50}(\mu \mathrm{g} / \mathrm{ml})$ \\
\hline DP-2 & -0.917 & 0.0000263 & 194.8 & -0.919 & 0.0000239 & 143.1 \\
\hline DP-3 & -0.804 & 0.00163 & 210.8 & -0.513 & 0.0882 & ND \\
\hline DP-4 & -0.923 & 0.0000185 & 200.0 & -0.936 & 0.00000741 & 164.1 \\
\hline DP-5 & -0.983 & $1.15 \times 10^{-8}$ & 126.3 & -0.738 & 0.00616 & 209.9 \\
\hline DP-6 & -0.929 & 0.0000129 & 201.1 & -0.9 & 0.0000674 & 152.6 \\
\hline DP-7 & -0.821 & 0.00106 & 288.7 & -0.736 & 0.00631 & 211.2 \\
\hline DP-8 & -0.944 & 0.00000397 & 137.9 & -0.945 & 0.00000356 & 125.7 \\
\hline DP-9 & -0.939 & 0.00000584 & 81.9 & -0.923 & 0.0000189 & 137.8 \\
\hline DP-10 & -0.494 & 0.103 & ND & -0.565 & 0.0558 & ND \\
\hline DP-11 & -0.966 & $3.53 \times 10^{-7}$ & 165.9 & -0.931 & 0.0000107 & 146.9 \\
\hline DP-12 & -0.824 & 0.000978 & 162.6 & -0.791 & 0.00216 & 248.5 \\
\hline M-Gal & 0.331 & 0.293 & ND & -0.78 & 0.00275 & 130.7 \\
\hline Q-Gal & -0.833 & 0.000757 & 164.8 & -0.896 & 0.000082 & 132.7 \\
\hline Q-Glu & -0.899 & 0.0000684 & 160.6 & -0.929 & 0.000013 & 160.6 \\
\hline Q-A-P & -0.665 & 0.0182 & 410.2 & -0.777 & 0.00293 & 212.7 \\
\hline Q-A-F & -0.791 & 0.00217 & 173.5 & -0.908 & 0.0000435 & 171.2 \\
\hline Q-Xylo & 0.095 & 0.77 & ND & -0.266 & 0.404 & ND \\
\hline Q-Rhamno & -0.879 & 0.000167 & 207.4 & -0.945 & 0.00000369 & 163.4 \\
\hline Q-Aglycone & -0.982 & $1.45 \times 10^{-8}$ & 83.2 & -0.966 & $3.48 \times 1^{0-7}$ & 61.1 \\
\hline
\end{tabular}

${ }^{a}$ Linear regression was conducted for each cranberry flavonoid between cell viability and compound concentration (untransformed and logarithmtransformed). $\mathrm{IC}_{50}$ value was calculated based on best-fit regression model ( $\mathrm{r}$ closer to -1). ND, not determined; M-Gal, myricetin-3-galactoside; Q-Gal, quercetin-3-galactoside; Q-Glu, quercetin-3-glucoside; Q-A-P, quercetin-3-arabinopyranoside; Q-A-F, quercetin-3-arabinofuranoside; Q-Xylo, quercetin-3-xylopyranoside; Q-Rhamno, quercetin-3-rhamnopyranoside; Q-Aglycone, quercetin aglycone.

SKOV-3 and OVCAR-8 cells. Cytotoxicity values for individual flavonoids and statistical analysis including p-values and correlation coefficients are provided in Table I.

Quercetin aglycone and PAC DP-9 induced apoptosis and increased cisplatin sensitivity in SKOV-3 and OVCAR-8 cells. To examine whether apoptosis was induced in ovarian cancer cells upon treatment with cranberry flavonoids, western blot and DNA fragmentation analysis (TUNEL assay) were carried. As shown in Fig. 3A, quercetin aglycone induced caspase-3 activation in both SKOV-3 and OVCAR-8 cells, and PAC DP-9 led to caspase- 3 and cleaved-PARP expression specifically in SKOV-3 cells.

TUNEL assay was performed to detect apoptosis-induced DNA fragmentation. Quercetin aglycone and PAC DP-9 treated cells showed apoptosis-induced DNA fragmentation, which was detected in both SKOV-3 and OVCAR- 8 cells after $12 \mathrm{~h}$ of treatment (Fig. 3B). Both western blot and DNA fragmentation analysis confirmed apoptosis induction in ovarian cancer cells exposed to these two cranberry flavonoids.

To investigate whether quercetin aglycone and PAC DP-9 could sensitize ovarian cancer cells to cisplatin, cells were pretreated with subtoxic concentrations of quercetin aglycone or PAC DP-9 for $6 \mathrm{~h}$, exposed to cisplatin overnight for $12 \mathrm{~h}$, and cell viability was analyzed. As shown in Fig. 3C, while subtoxic concentrations of quercetin aglycone or PAC DP-9 alone did not reduce SKOV-3 and OVCAR-8 cell viability, their pretreatment significantly reduced viability of cisplatintreated SKOV-3 and OVCAR-8 cells, with quercetin aglycone acting more strongly than PAC DP-9. Thus, quercetin aglycone and PAC DP-9 at low concentrations sensitize the response of cisplatin-resistant ovarian cancer cells to cisplatin, resulting in enhanced cytotoxicity.

PAC DP-9 downregulated expression and activation of epidermal growth factor receptor (EGFR) in SKOV-3 cells and induced EGFR nuclear translocation. Elevated EGFR expression results in poor prognosis in lung, breast and ovarian cancer (15). EGFR expression in quercetin aglycone or PAC DP-9 treated ovarian cancer cells was analyzed by immunoblotting and immunofluorescence microscopy. To eliminate the effect of serum growth factors on cellular EGFR regulation, ovarian cancer cells were serum-deprived for $4 \mathrm{~h}$ prior to treatment, and low concentrations $(5-40 \mu \mathrm{g} / \mathrm{ml})$ of cranberry flavonoids were applied with serum-free medium to avoid cell toxicity. After $12 \mathrm{~h}$ of treatment, quercetin aglycone did not affect phosphorylated-EGFR levels in either SKOV-3 or OVCAR-8 cells, but PAC DP-9 induced a dose-dependent 
A

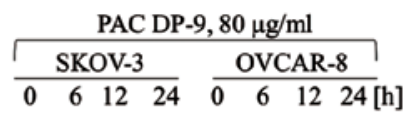

Cleaved caspase-3

Cleaved PARP

$\beta$-tubulin

\begin{tabular}{|c|c|}
\hline \multicolumn{2}{|c|}{ Quercetin aglycone, $80 \mu \mathrm{g} / \mathrm{ml}$} \\
\hline SKOV-3 & OVCAR-8 \\
\hline
\end{tabular}

Cleaved caspase-3

$\beta$-tubulin
B

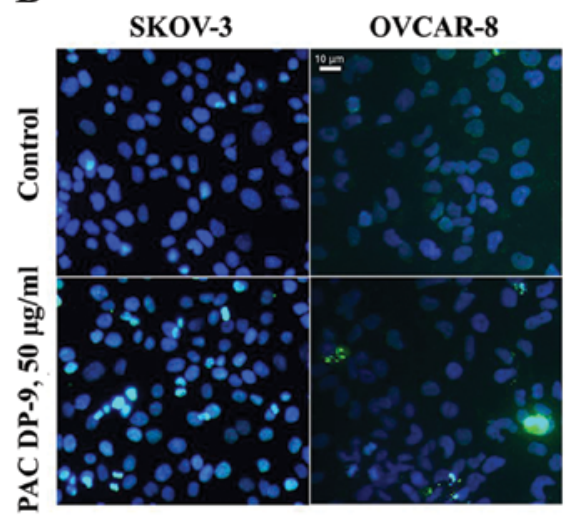

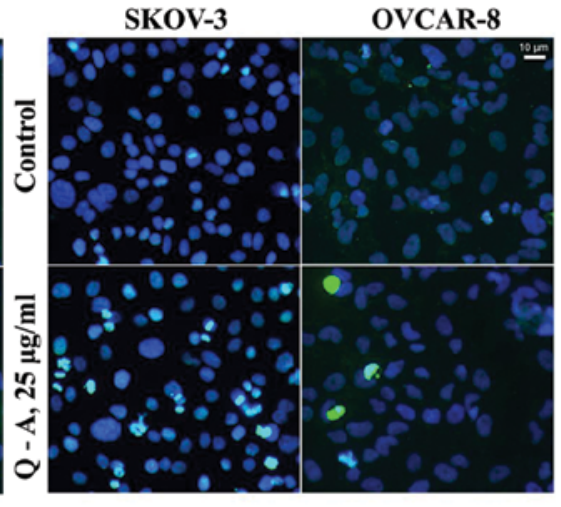

C
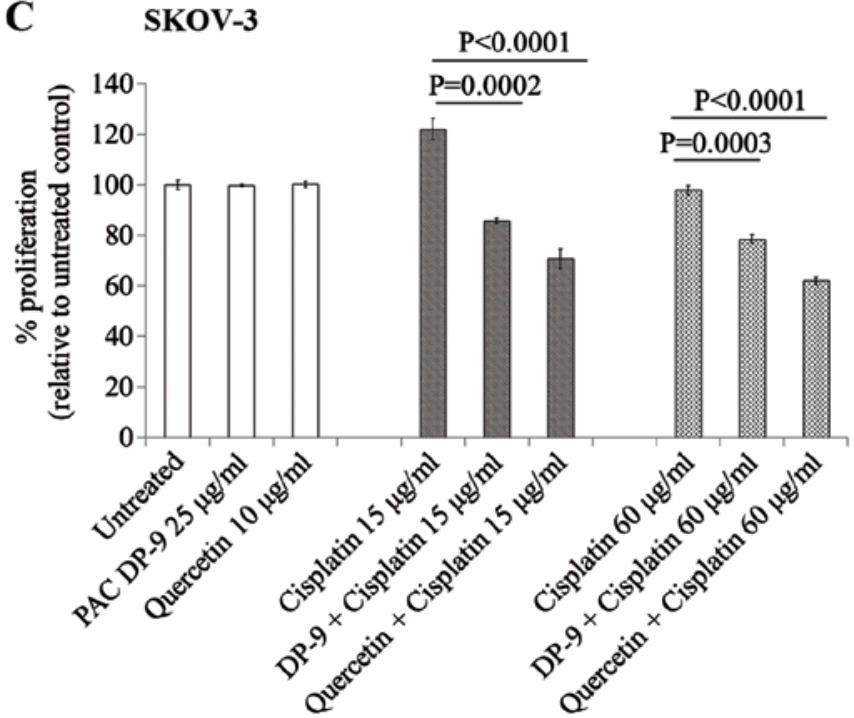

OVCAR-8

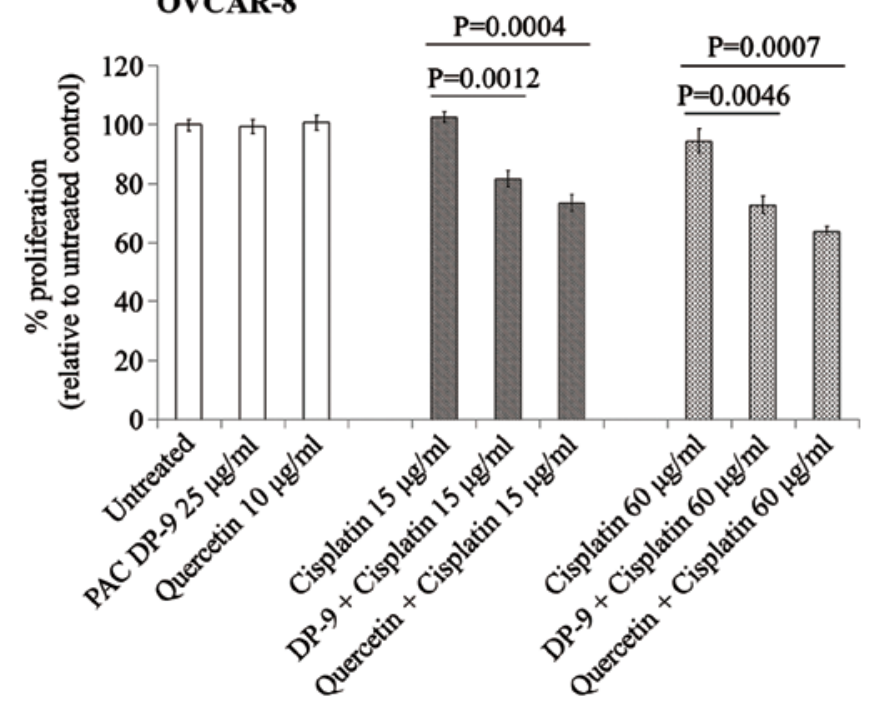

Figure 3. Induction of apoptosis (A and B) and sensitization to cisplatin (C) by quercetin aglycone and PAC DP-9 in SKOV-3 and OVCAR-8 cells. (A) Expression of cleaved caspase-3 and cleaved PARP after treatment with PAC DP-9 and quercetin aglycone. Ovarian cancer cells were treated with PAC DP-9 or quercetin aglycone $(80 \mu \mathrm{g} / \mathrm{ml})$ for $0-24 \mathrm{~h}$. Actin or tubulin were probed as internal loading controls; (B) TUNEL assay in PAC DP-9 and quercetin aglycone (Q-A)-treated SKOV-3 and OVCAR-8 cells. Cells were treated with PAC DP-9 $(50 \mu \mathrm{g} / \mathrm{ml})$, quercetin aglycone ( $25 \mu \mathrm{g} / \mathrm{ml})$ or DMSO vehicle for $12 \mathrm{~h}$. DNA strand breaks due to apoptosis were detected and labelled by fluorescein-labelled nucleotides (green). (C) Cell viability of cranberry flavonoid and cisplatin-treated SKOV-3 and OVCAR- 8 cells. Cells were pre-treated with either DMSO vehicle, PAC DP-9 $(25 \mu \mathrm{g} / \mathrm{ml})$, or quercetin aglycone (10 $\mu \mathrm{g} / \mathrm{ml})$ for $6 \mathrm{~h}$ in complete DMEM media, followed by cisplatin treatment alone or cisplatin + PAC DP-9/quercetin aglycone. Cells were incubated overnight for $12 \mathrm{~h}$ and analyzed via MTS for viability. Experiments were performed in triplicate; data are expressed as mean \pm SD in percent of cell viability of untreated cells (100\%).

downregulation of both phosphorylated-EGFR and total EGFR in SKOV-3 cells (Fig. 4A). As shown in Fig. 4B, EGFR was expressed predominantly at the cell membrane in the untreated controls, and exhibited nuclear translocation within $3 \mathrm{~h}$ of treatment with PAC DP-9 in a dose-dependent manner such that lower concentrations (12.5-25 $\mu \mathrm{g} / \mathrm{ml})$ induced EGFR peri-nuclear localization in SKOV-3 cells, and higher concentrations (50-200 $\mu \mathrm{g} / \mathrm{ml})$ of PAC DP-9 mediated EGFR nuclear translocation.

Quercetin aglycone and PAC DP-9 downregulated prosurvival MAP kinase proteins in ovarian cancer cells. We examined changes in MAP kinase signaling regulation exerted by quercetin aglycone and PAC DP-9 in ovarian cancer cells. Expression of MEK (Fig. 5A) and phospho-ERK1/2 (Fig. 5B) was downregulated after $12 \mathrm{~h}$ of treatment with quercetin aglycone or PAC DP-9, indicating inhibition of pro-survival MAPK-ERK signal transduction by cranberry flavonoids.
Similarly, treatment with quercetin aglycone and PAC-9 led to rapid, significant downregulation of phospho-p42/22 MAPK and phospho-c-Raf in OVCAR- 8 cells within $6 \mathrm{~h}$ (Fig. 6A), demonstrating their inhibitory effect on the activated prosurvival MAPK pathway.

Quercetin aglycone and PAC DP-9 affected cell cycle progression of ovarian cancer cells. Immunofluorescence microscopy analysis of quercetin aglycone and PAC DP-9 treatment revealed downregulation of cyclin D1 and upregulation of p21 in SKOV-3 and OVCAR-8 cells (Fig. 5D and F). Phospho-histone H3 (Fig. 5C) and DNA-dependent protein kinase (DNA-PK, Fig. 5E), proteins often overexpressed in ovarian cancer cells, were also downregulated in SKOV-3 and OVCAR-8 cells upon treatment with cranberry flavonoids. Based on immunoblot study, phospho-p53 and p21 expression were first downregulated after $6 \mathrm{~h}$ of treatment with quercetin aglycone in OVCAR- 8 cells and then exhibited sustained 
A

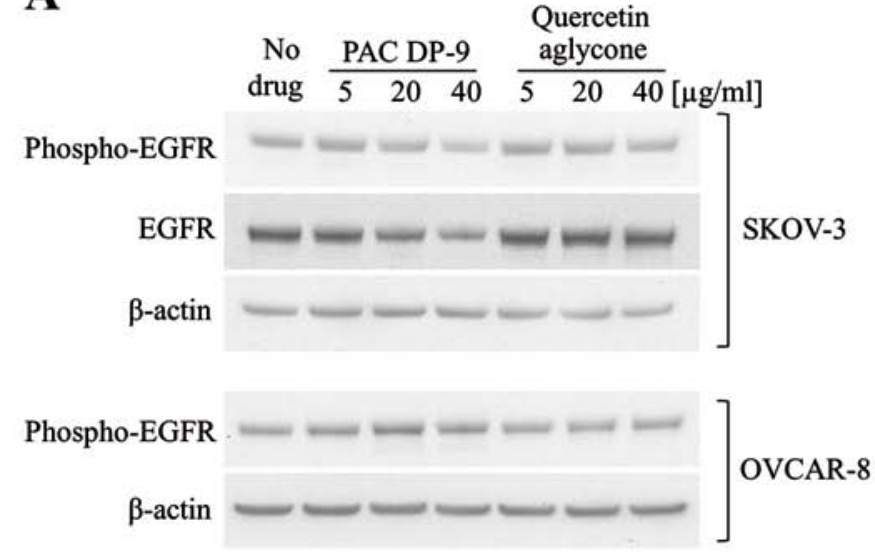

Figure 4. Effects of quercetin aglycone and PAC DP-9 on expression, activation and localization of EGFR in SKOV-3 and OVCAR-8 cells. (A) Expression of total and activated EGFR on cranberry flavonoid treated SKOV-3 and OVCAR- 8 cells. Cells were serum-deprived for $4 \mathrm{~h}$ and then treated with 5,20 or $40 \mu \mathrm{g} / \mathrm{ml}$ quercetin aglycone or PAC DP-9 in serum-free DMEM medium for $12 \mathrm{~h}$. Actin was probed as internal loading control. (B) Effects of PAC DP-9 on EGFR expression and localization in SKOV-3 cells. Cells were treated with different concentrations $(12.5-200 \mu \mathrm{g} / \mathrm{ml})$ of PAC DP-9 for $3 \mathrm{~h}$ before fluorescent microscopic analysis. EGFR was visualized by Alexa Fluor 594 secondary antibody (red), and nuclei were stained with DAPI.

upregulation (Fig. 6A). Three other cell cycle regulators, p18, p27, and CDK2 were also upregulated within 6-24 h of treatment with quercetin aglycone. Independent of p53 expression, SKOV-3 cells exhibited rapid upregulation of cell cycle inhibitor p21 after $6 \mathrm{~h}$ of treatment of quercetin aglycone, together with upregulation of p18, p27, and CDK2 within $24 \mathrm{~h}$ of treatment. Similarly, PAC DP-9 induced upregulation of p21 in both SKOV-3 and OVCAR-8 cells within 6-24 h-treatment regardless of $\mathrm{p} 53$ expression level. CDK2 expression was also upregulated in SKOV-3 and OVCAR- 8 cells after $24 \mathrm{~h}$ of PAC DP-9 treatment.

Because immunofluorescence microscopy and western blot analysis showed inhibition of SKOV-3 cellular EGFR expression by PAC DP-9 (Fig. 4), co-immunoprecipitation (Co-IP) was utilized to examine potential protein-protein interactions involved with EGFR and cell cycle regulatory factors, including p18, p21, p27, CDK2, cyclin D1 and cyclin D3. While most of the probed proteins did not show a positive signal, CDK2 signal was detected in both SKOV-3 and OVCAR-8 EGFR Co-IP samples. As shown in Fig. 6B, CDK2 was recovered in both positive controls and two Co-IP samples as well as in the OVCAR- 8 negative control, indicating a false-positive signal in the OVCAR-8 Co-IP sample. The absence of CDK2 signal in SKOV-3 negative control confirmed direct interaction between CDK2 and EGFR in SKOV-3 cells.

Both western blot and Co-IP studies indicate a direct effect of cranberry flavonoids on ovarian cancer cell progression. Subpopulations of propidium iodide-stained SKOV-3 and OVCAR-8 ovarian cancer cells treated with cranberry flavonoids were analyzed by flow cytometry. As illustrated in Fig. 6C and D, quercetin aglycone or PAC DP-9 treatment
B

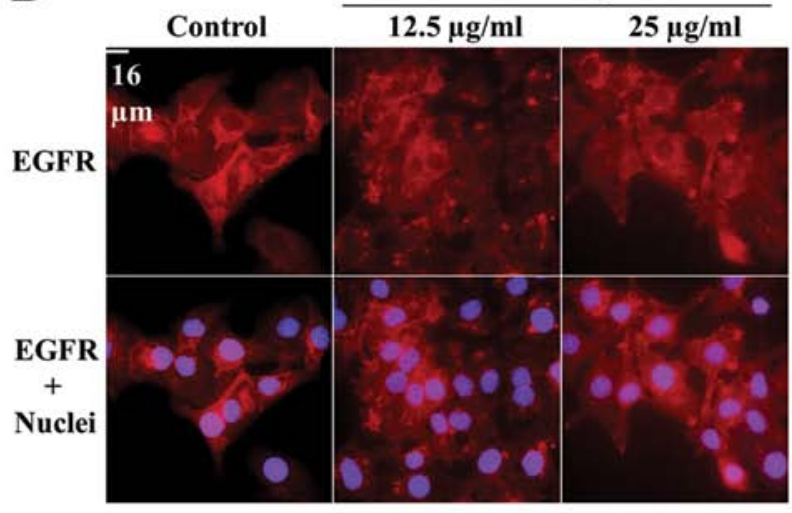

PAC DP-9, 3 h

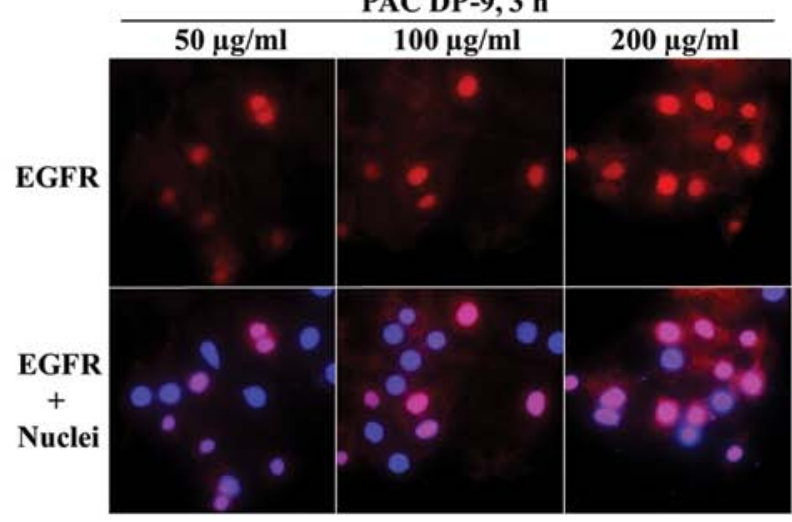

for $24 \mathrm{~h}$ in SKOV-3 cells led to G2/M-phase arrest dosedependently. The G2/M subpopulation increased from 10.81 to $16.52 \%$ for SKOV-3 cells treated with $50 \mu \mathrm{g} / \mathrm{ml}$ quercetin aglycone and further increased to $32.35 \%$ after treatment with $100 \mu \mathrm{g} / \mathrm{ml}$ quercetin aglycone. Similarly, 50 and $100 \mu \mathrm{g} /$ ml PAC DP-9 caused an increase in the SKOV-3 cell G2/M subpopulation to 17.69 and $29.63 \%$, respectively. After $48 \mathrm{~h}$ of treatment in SKOV-3 cells, PAC DP-9 exhibited similar dosedependent G2/M-phase arrest, whereas 50 and $100 \mu \mathrm{g} / \mathrm{ml}$ quercetin aglycone led to an increase in S subpopulation from 22.01 to 45.54 and $50.35 \%$, respectively, with no significant change in $\mathrm{G} 2 / \mathrm{M}$ subpopulation. This suggests that quercetin aglycone caused S/G2-phase arrest in SKOV-3 cells after $48 \mathrm{~h}$ of treatment.

Quercetin aglycone treatment for 24 and $48 \mathrm{~h}$ in OVCAR-8 cells caused G1/S-phase arrest. At $50 \mu \mathrm{g} / \mathrm{ml}$, quercetin aglycone led to retention of 75.69 and $86.12 \%$ of cells in G0/G1 phase after 24 and $48 \mathrm{~h}$ of treatment, respectively, and the subpopulation of S-phase cells decreased from 38.67 to $12.61 \%$ after $24 \mathrm{~h}$ and from 26.35 to $6.45 \%$ after $48 \mathrm{~h}$ (Fig. 6D). PAC DP-9 showed a similar effect in OVCAR-8 cells, thus confirming that G1/S-phase arrest was caused by the two compounds in OVCAR-8 ovarian cancer cells.

\section{Discussion}

Cranberry phenolic extracts have shown in vitro anticancer and chemo-preventive properties in different cancer cell lines (5-11). Research on individual phenolic compounds of cranberry has been limited by the difficulty of compound isolation due to complex structural variations, including degree-of- 
A

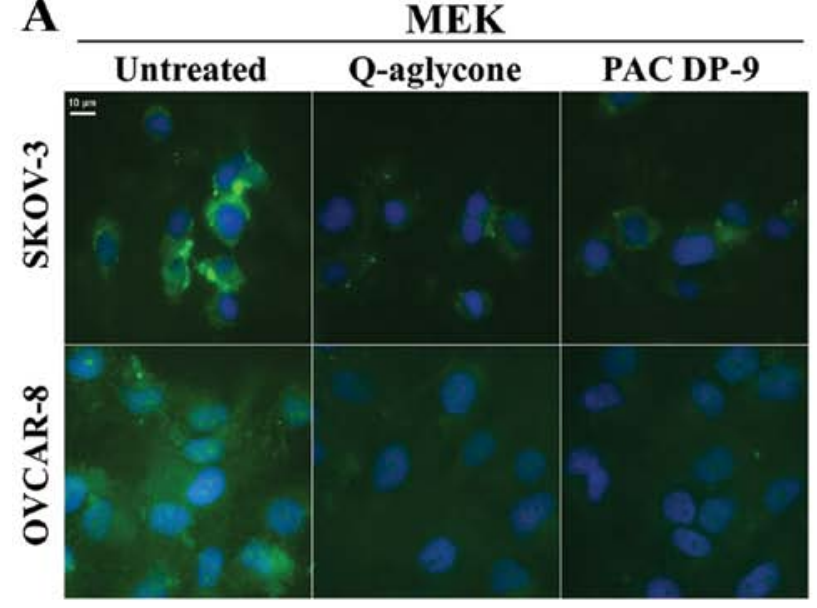

C

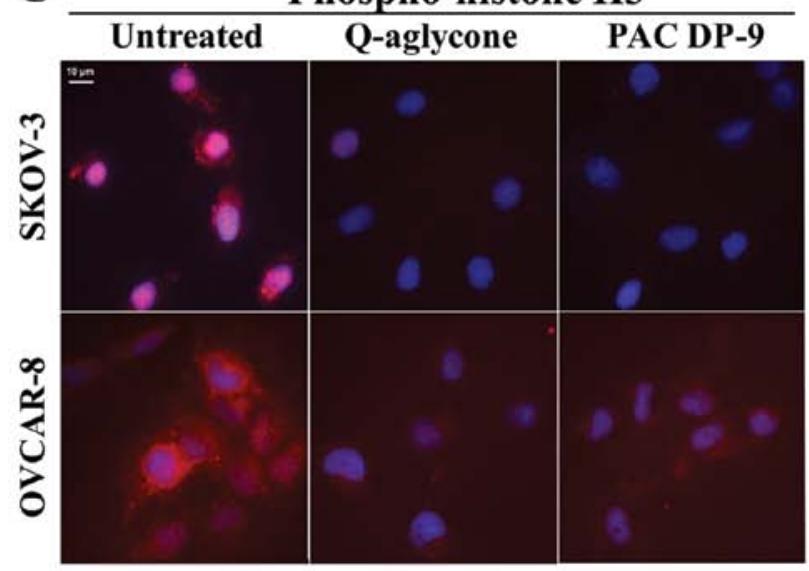

$\mathbf{E}$

DNA-PK

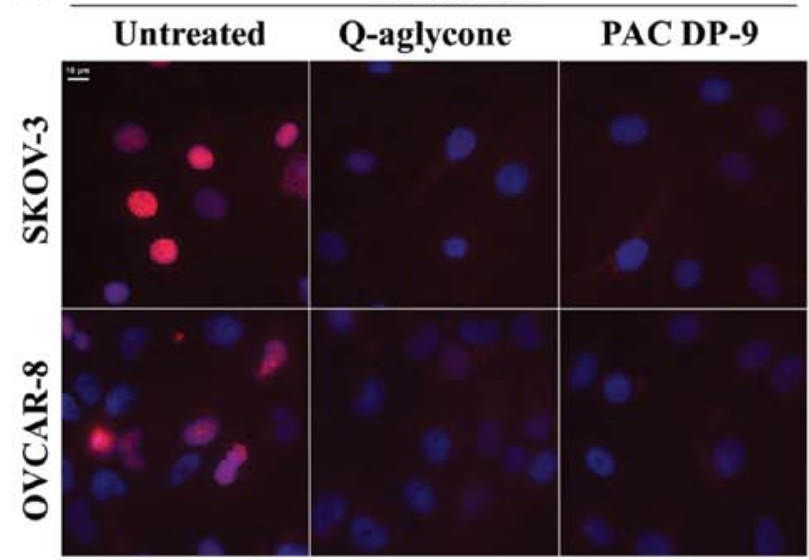

B

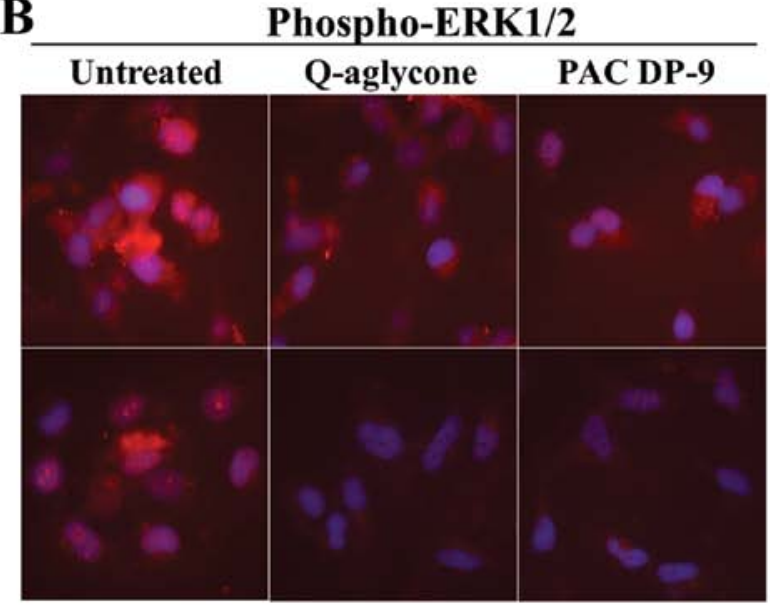

D

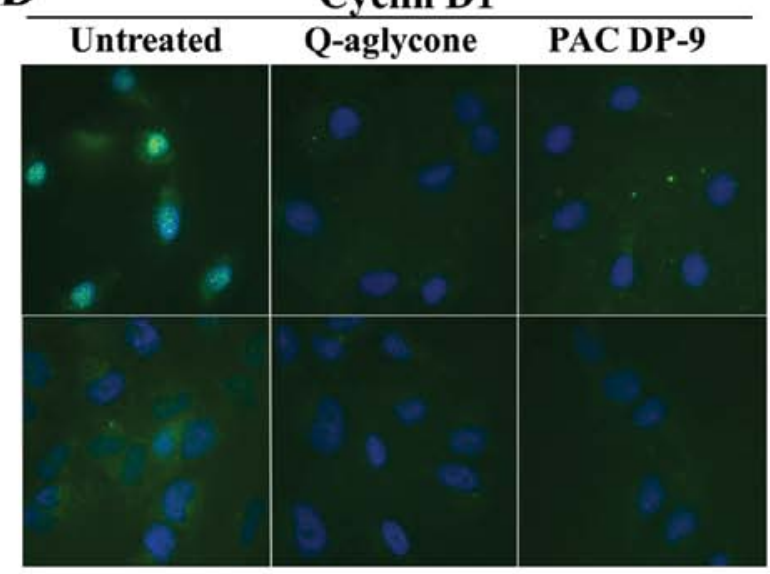

F

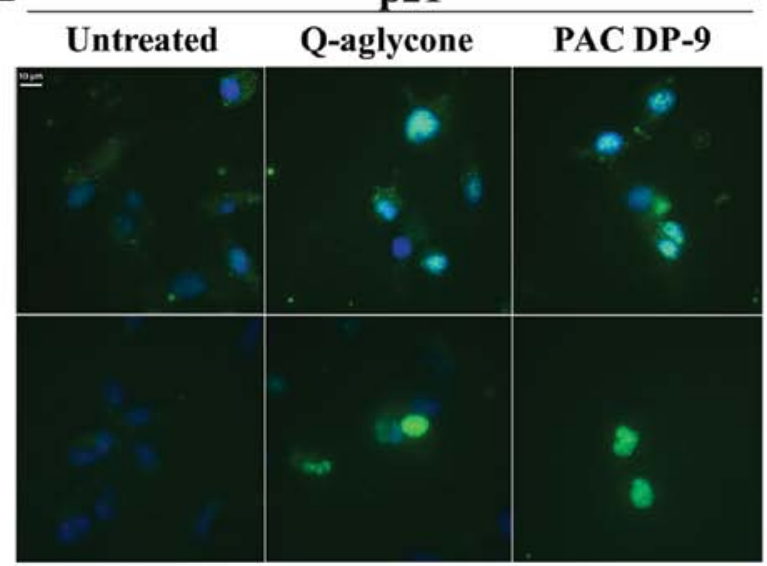

Figure 5. Effect of quercetin aglycone and PAC DP-9 (12-h treatment) on cellular expression of MEK (A), phospho-ERK1/2 (B), phospho-histone H3 (C), cyclin D1 (D), DNA-PK (E) and p21 (F) in SKOV-3 and OVCAR-8 cells. Cells were treated with either DMSO vehicle, PAC DP-9 (80 $\mu \mathrm{g} / \mathrm{ml})$, or quercetin aglycone $(80 \mu \mathrm{g} / \mathrm{ml})$ for $12 \mathrm{~h}$ and stained for target proteins. MEK, cyclin D1 and p21 were probed by DyLight 488 secondary antibody (green); phosphoERK1/2, phospho-histone H3 and DNA-PK were probed by DyLight 594 secondary antibody (red).

polymerization, linkage type, position of the double linkage between constituent units, and attachment with sugar moieties $(9,12)$. Serial application of Dionex UltiMate ${ }^{\circledR} 3000$ LC system consisting of UltiMate 3000 RS Pump, UltiMate 3000 RS Autosampler, UltiMate 3000 RS Column Compartment, and UltiMate 3000 RS Diode Array Detector coupled with Applied Biosystems API 3000 triple quad LC-MS/MS mass spectrometer has allowed the reproducible isolation and characterization of individual PACs with up to the 10th degree of polymerization in $>95 \%$ purity in our laboratories. So far, we have successfully isolated 19 high-purity individual cranberry flavonoids, characterized their structures by LC-APCI-MS, and used them as primary materials to determine bioactivity.

SKOV-3 and OVCAR-8 ovarian cell lines, which possess several key oncogenic hallmarks such as p53 mutation, EGFR overexpression, and cisplatin resistance (16-18), were employed as an in vitro cell culture model to determine the mechanism of action of cranberry flavonoids. Individual PACs DP-2 to 
A

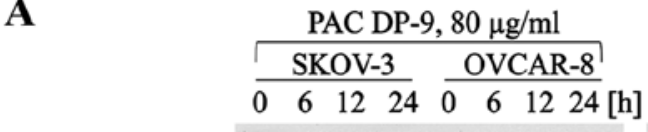

\section{Phospho-ERK1/2 \\ Phospho-C-Raf}

Phospho-p53

p18

p21

p27

CDK2

$\beta$-tubulin

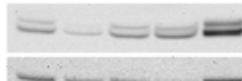

$----\cdots$
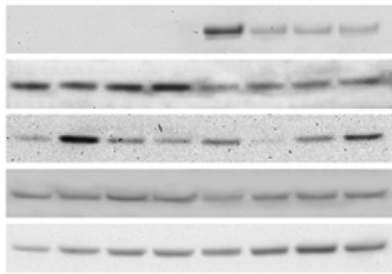

$-1+\frac{1}{-1}-1-$
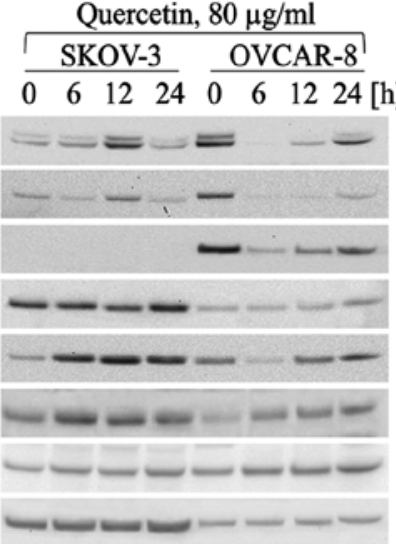

B

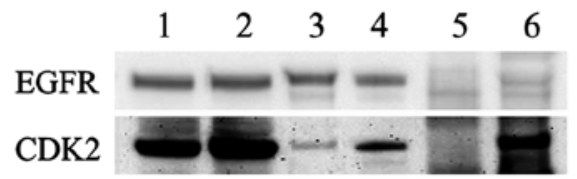

C
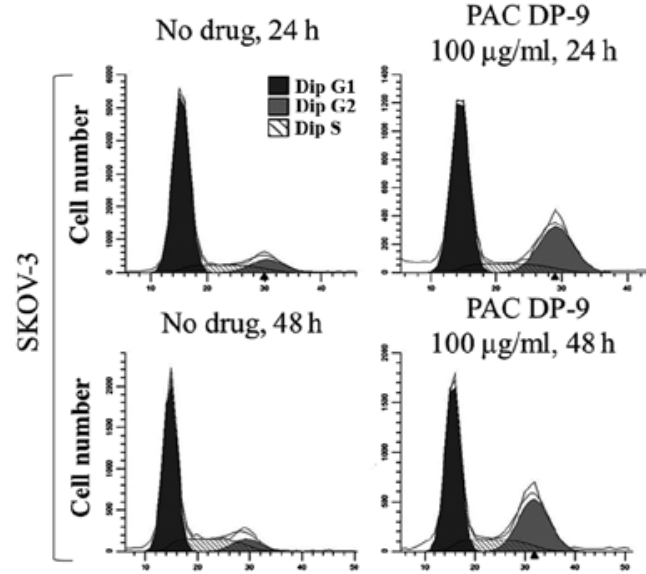

PAC DP-9

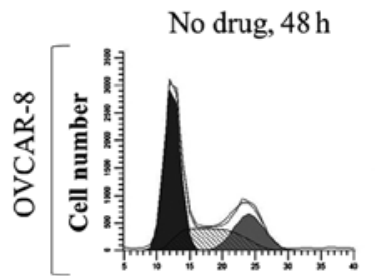

$100 \mu \mathrm{g} / \mathrm{ml}, 48 \mathrm{~h}$

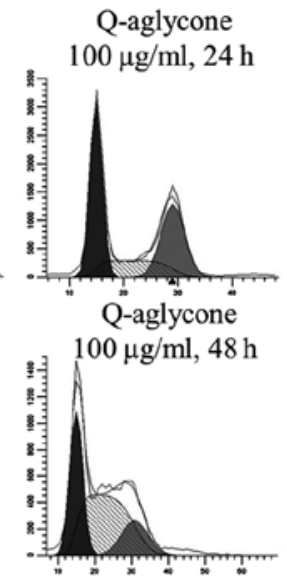

Q-aglycone $100 \mu \mathrm{g} / \mathrm{ml}, 48 \mathrm{~h}$

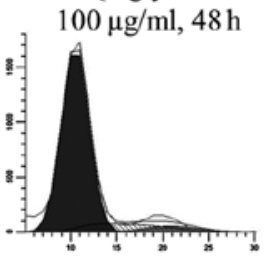

D

\begin{tabular}{|c|c|c|c|c|c|}
\hline $\begin{array}{c}\text { Incubation } \\
\text { time }[\mathrm{h}]\end{array}$ & Compound & $\begin{array}{c}\text { Concentration } \\
{[\mu \mathrm{g} / \mathrm{ml}]}\end{array}$ & $\begin{array}{c}\text { G0/G1 } \\
{[\%]}\end{array}$ & $\begin{array}{c}\mathrm{S} \\
{[\%]}\end{array}$ & $\begin{array}{c}\text { G2/M } \\
{[\%]}\end{array}$ \\
\hline \multirow{5}{*}{24} & No drug & 0 & 76.7 & 12.49 & 10.81 \\
\hline & \multirow{2}{*}{$\begin{array}{l}\text { Quercetin } \\
\text { aglycone }\end{array}$} & 50 & 64.24 & 19.24 & 16.52 \\
\hline & & 100 & 52.48 & 15.17 & 32.35 \\
\hline & \multirow{2}{*}{ PAC DP-9 } & 50 & 70.43 & 11.88 & 17.69 \\
\hline & & 100 & 58.58 & 11.79 & 29.63 \\
\hline \multirow{5}{*}{48} & No drug & 0 & 68.05 & 22.01 & 9.94 \\
\hline & \multirow{2}{*}{$\begin{array}{l}\text { Quercetin } \\
\text { aglycone }\end{array}$} & 50 & 43.61 & 45.54 & 10.85 \\
\hline & & 100 & 33.3 & 50.35 & 16.36 \\
\hline & \multirow{2}{*}{ PAC DP-9 } & 50 & 64.24 & 19.24 & 16.52 \\
\hline & & 100 & 52.48 & 15.17 & 32.35 \\
\hline
\end{tabular}

\begin{tabular}{|c|c|c|c|c|c|}
\hline \multicolumn{6}{|c|}{ OVCAR-8 } \\
\hline $\begin{array}{c}\text { Incubation } \\
\text { time }[\mathrm{h}]\end{array}$ & Compound & $\begin{array}{c}\text { Concentration } \\
{[\mu \mathrm{g} / \mathrm{ml}]}\end{array}$ & $\begin{array}{c}\mathrm{G} 0 / \mathrm{G} 1 \\
{[\%]}\end{array}$ & $\begin{array}{c}\mathrm{S} \\
{[\%]}\end{array}$ & $\begin{array}{c}\mathrm{G} 2 / \mathrm{M} \\
{[\%]}\end{array}$ \\
\hline \multirow{5}{*}{24} & No drug & 0 & 33.39 & 38.67 & 27.94 \\
\hline & \multirow{2}{*}{$\begin{array}{l}\text { Quercetin } \\
\text { aglycone }\end{array}$} & 50 & 75.69 & 12.61 & \begin{tabular}{|l|}
11.7 \\
\end{tabular} \\
\hline & & 100 & 70.26 & 15.5 & 14.24 \\
\hline & \multirow{2}{*}{ PAC DP-9 } & 50 & 56.03 & 33.6 & 10.37 \\
\hline & & 100 & 61.09 & 30.47 & 8.44 \\
\hline \multirow{5}{*}{48} & No drug & 0 & 52.19 & 26.35 & 21.46 \\
\hline & \multirow{2}{*}{$\begin{array}{l}\text { Quercetin } \\
\text { aglycone }\end{array}$} & 50 & 86.12 & 6.45 & 7.43 \\
\hline & & 100 & 83.9 & 10.8 & 5.3 \\
\hline & \multirow{2}{*}{ PAC DP-9 } & 50 & 47.55 & 34.18 & 18.28 \\
\hline & & 100 & 63.44 & 27.36 & 9.2 \\
\hline
\end{tabular}

Figure 6. Effect of PAC DP-9 and quercetin aglycone on cell cycle regulation in SKOV-3 and OVCAR-8 cells. (A) Western blot analysis of ERK-MAPK signal components and cell cycle regulatory factors in SKOV-3 and OVCAR- 8 cells after treatment with quercetin aglycone or PAC DP-9 (80 $\mu \mathrm{g} / \mathrm{ml})$ for 0-24 h. Tubulin was probed as an internal loading control; (B) EGFR co-immunoprecipitation on SKOV-3 and OVCAR-8 cell lysates. 1, SKOV-3 untreated input control; 2, OVCAR-8 untreated input control; 3, SKOV-3 EGFR-co-immunoprecipitation; 4, OVCAR-8 EGFR-co-immunoprecipitation; 5, SKOV-3 IgG-co-immunoprecipitation control; 6, OVCAR-8 IgG-co-immunoprecipitation control. (C and D) Determination of cell cycle progression by FACS analysis in SKOV-3 and OVCAR-8 cells treated with 50 or $100 \mu \mathrm{g} / \mathrm{ml}$ quercetin aglycone or PAC DP-9 for 24-48 h. Data are presented as relative fluorescence intensity of $\mathrm{G} 0 / \mathrm{G} 1, \mathrm{~S}$ and $\mathrm{G} 2 / \mathrm{M}$ phase subpopulations in 2-D charts (C) or tables (D).

DP-4 failed to show strong cytotoxicity against SKOV-3 cells, and high molecular weight PAC polymers generally exhibited stronger cytotoxicity similar to what we showed earlier (9). Quercetin aglycone emerged as the most cytotoxic of the tested cranberry flavonols. Shen et al showed that quercetin aglycone exhibited significantly higher cytotoxicity against human promyelocytic leukemia cells HL-60 compared to its rutinose and rhamnose glycosides (19). Murota et al also reported that quercetin aglycone was much more efficiently absorbed by Caco-2 colorectal adenocarcinoma cells than its glycosides (20). Both quercetin aglycone and PAC DP-9 induced ovarian cancer cell death through apoptotic events, and subtoxic concentrations of the two compounds significantly increased the efficacy of cisplatin against ovarian cancer cells. Because developed resistance to platinum-based drugs is one of the major causes of mortality in ovarian cancer (2), the observation that cranberry flavonoids can sensitize drug-resistant ovarian cancer cells to cisplatin provides an opportunity to improve the efficacy of platinum chemotherapies and reduce side effects associated with cisplatin.

EGFR, a receptor tyrosine kinase, is involved in many signaling pathways that modulate cell survival, proliferation and apoptosis. Aberrant activation of EGFR has been shown to play a critical role in cancer cell survival and develop- 
ment $(18,21)$. B-type PACs isolated from grape seeds have been shown to target and downregulate EGFR expression in human head and neck squamous cell carcinoma (HNSCC) cells and inhibited their invasiveness (22). Our study showed that treatment with A-type PAC DP-9 decreased expression and activation and induced nuclear translocation of EGFR in SKOV-3 cells dose-dependently. Association of EGFR with DNA-PK, which is involved in DNA repair, has been previously reported $(23,24)$, and its nuclear translocation has been confirmed to modulate DNA repair caused by cisplatin or radiation in mouse fibroblast cell lines (25). Although EGFR nuclear translocation can be expected to activate DNA-PK as a counter measure to DNA damage due to quercetin and PAC-9 treatment, immunofluorescence microscopy analysis revealed downregulation of DNA-PK in ovarian cancer cells exposed to quercetin aglycone or PAC DP-9. The DNA-PK-mediated DNA repair that is induced by exposure to cisplatin in cancer cells is believed to be an important factor in reducing the efficacy of platinum-based chemotherapy $(26,27)$. Therefore, the inhibition of DNA-PK expression in quercetin aglycone or PAC DP-9-treated ovarian cancer cells may partially account for the increased efficacy of cisplatin in ovarian cancer cells following quercetin aglycone or PAC DP-9 pre-treatment.

EGFR also regulates the extracellular signal-regulated kinase ERK-MAPK pathway to maintain normal cell growth, proliferation and differentiation (28). Aberrant activation of the EGFR-Ras-Raf-MEK-ERK cascade is believed to contribute to cancer development and progression (29). Both quercetin aglycone and PAC DP-9 downregulated activated Raf, ERK1/2 and MEK in OVCAR- 8 cells, suggesting the ERK-MAPK pathway may be one of the anti-proliferative mechanisms. The Raf-MEK-ERK pathway is also known to control cell cycle progression through induction of key cell cycle regulatory factors such as cyclins, cyclin-dependent kinases (CDKs), and p21 (30). Phosphorylation of histone H3, which is believed to play an important role in cell division and oncogene induction, was shown to be stimulated by Ras-MAPK signaling pathway $(31,32)$. In our study, we report different levels of upregulation of CDK inhibitors p18, p27, and most significantly, p21 after treatment with quercetin aglycone or PAC DP-9, as well as downregulation of cyclin D1 and phospho-histone H3, indicating their effects on cell cycle regulation. Expression of p21 can be induced by either p53-dependent or independent pathways $(33,34)$. In SKOV-3 cells, where the p53 gene is mutated and loses its expression, PAC DP-9 induced p21 upregulation inversely correlated with the expression of ERK1/2, suggesting that PAC DP-9 modulated a p53-independent ERK pathway that mediates p21 regulation similar to a published mechanism in rhabdosarcoma cells (34).

Upregulation of CDK inhibitors and downregulation of cyclin D1 and phospho-histone H3 induced by the two cranberry flavonoids reflected the ability of quercetin aglycone and PAC DP-9 to cause cell cycle arrest in SKOV-3 and OVCAR-8 cells. At concentrations lower than $\mathrm{IC}_{50}$, both quercetin aglycone and PAC DP-9 induced G1/S phase cell cycle arrest in OVCAR-8 cells, consistent with the upregulation of cellular p21 that has been shown to inhibit CDK regulation in G1/S phase progression (35). On the other hand, SKOV-3 cells showed cell cycle arrest at G2/M phase within $24 \mathrm{~h}$ of treatment with quercetin aglycone or PAC DP-9, similar as shown previously (10). Interestingly, CDK2, which is inhibited by p21 and facilitates G1/S phase transition (35), was upregulated after treatment with quercetin aglycone or PAC DP-9 in both SKOV-3 and OVCAR- 8 cells. We confirmed direct proteinprotein interaction between EGFR and CDK2 in SKOV-3 cells through Co-IP, suggesting that CDK-2 overexpression could be induced by nuclearly localized EGFR to facilitate DNA repair and synthesis after exposure to quercetin aglycone or PAC DP-9. These observations suggest that cell division of the two ovarian cancer cell lines was regulated through different mechanisms by cranberry flavonoids. Targeting cell cycle checkpoints has been proposed as a promising approach to cancer treatment (36).

In conclusion, our study suggests that certain cranberry flavonols and PACs possess cytotoxic properties against ovarian cancer cells. The integration of quercetin and/or PAC DP-9 in ovarian cancer chemotherapy may provide for improved outcomes. Quercetin aglycone and PAC DP-9 induced cellular apoptotic events including cell cycle arrest and suppression of DNA repair pathways that highlight their potential as dietarily available therapeutic agents.

\section{Acknowledgements}

Y.W., A.P.S. and N.V. are grateful to National Institutes of Health (NIH) for funding support via grant 5R01DE016139.

\section{References}

1. Jacobs IJ and Menon U: Progress and challenges in screening for early detection of ovarian cancer. Mol Cell Proteomics 3: 355-366, 2004.

2. Agarwal R and Kaye SB: Ovarian cancer: Strategies for overcoming resistance to chemotherapy. Nat Rev Cancer 3: 502-516, 2003.

3. American Cancer Society: Ovarian Cancer Key Statistics (http:// www.cancer.org/cancer/ovariancancer/index), 2014.

4. Foo LY, Lu Y, Howell AB and Vorsa N: A-Type proanthocyanidin trimers from cranberry that inhibit adherence of uropathogenic P-fimbriated Escherichia coli. J Nat Prod 63: 1225-1228, 2000.

5. Seeram NP, Adams LS, Hardy ML and Heber D: Total cranberry extract versus its phytochemical constituents: Antiproliferative and synergistic effects against human tumor cell lines. J Agric Food Chem 52: 2512-2517, 2004.

6. Neto CC: Cranberry and its phytochemicals: A review of in vitro anticancer studies. J Nutr 137 (Suppl): S186-S193, 2007.

7. Neto CC, Krueger CG, Lamoureaux TL, et al: MALDI-TOFMS characterization of proanthocyanidins from cranberry fruit (Vaccinium macrocarpon) that inhibit tumor cell growth and matrix metalloproteinase expression in vitro. J Sci Food Agric 86: $18-25,2006$.

8. Ferguson PJ, Kurowska E, Freeman DJ, Chambers AF and Koropatnick DJ: A flavonoid fraction from cranberry extract inhibits proliferation of human tumor cell lines. J Nutr 134: 1529-1535, 2004

9. Singh AP, Singh RK, Kim KK, Satyan KS, Nussbaum R, Torres M, Brard L and Vorsa N: Cranberry proanthocyanidins are cytotoxic to human cancer cells and sensitize platinum-resistant ovarian cancer cells to paraplatin. Phytother Res 23: 1066-1074, 2009.

10. Kim KK, Singh AP, Singh RK, Demartino A, Brard L, Vorsa N, Lange TS and Moore RG: Anti-angiogenic activity of cranberry proanthocyanidins and cytotoxic properties in ovarian cancer cells. Int J Oncol 40: 227-235, 2012.

11. Singh AP, Lange TS, Kim KK, Brard L, Horan T, Moore RG, Vorsa N and Singh RK: Purified cranberry proanthocyanidines (PAC-1A) cause pro-apoptotic signaling, ROS generation, cyclophosphamide retention and cytotoxicity in high-risk neuroblastoma cells. Int J Oncol 40: 99-108, 2012.

12. Vvedenskaya IO, Rosen RT, Guido JE, Russell DJ, Mills KA and Vorsa N: Characterization of flavonols in cranberry (Vaccinium macrocarpon) powder. J Agric Food Chem 52: 188-195, 2004. 
13. Wilson T, Singh AP, Vorsa N, Goettl CD, Kittleson KM, Roe CM Kastello GM and Ragsdale FR: Human glycemic response and phenolic content of unsweetened cranberry juice. J Med Food 11: 46-54, 2008

14. Singh AP, Wilson T, Kalk AJ, Cheong J and Vorsa N: Isolation of specific cranberry flavonoids for biological activity assessment. Food Chem 116: 963-968, 2009.

15. Nicholson RI, Gee JMW and Harper ME: EGFR and cancer prognosis. Eur J Cancer 37 (Suppl 4): S9-S15, 2001.

16. Schilder RJ, Hall L, Monks A, Handel LM, Fornace AJ Jr, Ozols RF, Fojo AT and Hamilton TC: Metallothionein gene expression and resistance to cisplatin in human ovarian cancer. Int J Cancer 45: 416-422, 1990.

17. Bacchetti $S$ and Graham F: Inhibition of cell-proliferation by an adenovirus vector expressing the human wild type-p53 protein. Int J Oncol 3: 781-788, 1993.

18. Anderson NG, Ahmad T, Chan K, Dobson R and Bundred NJ: ZD1839 (Iressa), a novel epidermal growth factor receptor (EGFR) tyrosine kinase inhibitor, potently inhibits the growth of EGFR-positive cancer cell lines with or without erbB2 overexpression. Int J Cancer 94: 774-782, 2001.

19. Shen SC, Chen YC, Hsu FL and Lee WR: Differential apoptosis-inducing effect of quercetin and its glycosides in human promyeloleukemic HL-60 cells by alternative activation of the caspase 3 cascade. J Cell Biochem 89: 1044-1055, 2003.

20. Murota K, Shimizu S, Chujo H, Moon JH and Terao J: Efficiency of absorption and metabolic conversion of quercetin and its glucosides in human intestinal cell line Caco-2. Arch Biochem Biophys 384: 391-397, 2000.

21. Yarden Y: The EGFR family and its ligands in human cancer. signalling mechanisms and therapeutic opportunities. Eur J Cancer 37 (Suppl 4): S3-S8, 2001.

22. Sun Q, Prasad R, Rosenthal E and Katiyar SK: Grape seed proanthocyanidins inhibit the invasiveness of human HNSCC cells by targeting EGFR and reversing the epithelial-to-mesenchymal transition. PLoS One 7: e31093-e31093, 2012.

23. Rodemann HP, Dittmann K and Toulany M: Radiation-induced EGFR-signaling and control of DNA-damage repair. Int J Radiat Biol 83: 781-791, 2007.

24. Wang SC and Hung MC: Nuclear translocation of the epidermal growth factor receptor family membrane tyrosine kinase receptors. Clin Cancer Res 15: 6484-6489, 2009.
25. Liccardi G, Hartley JA and Hochhauser D: EGFR nuclear translocation modulates DNA repair following cisplatin and ionizing radiation treatment. Cancer Res 71: 1103-1114, 2011.

26. Jamieson ER and Lippard SJ: Structure, recognition, and processing of cisplatin-DNA adducts. Chem Rev 99: 2467-2498, 1999.

27. Jung Y and Lippard SJ: Direct cellular responses to platinuminduced DNA damage. Chem Rev 107: 1387-1407, 2007.

28. Stokoe D, Macdonald SG, Cadwallader K, Symons M and Hancock JF: Activation of Raf as a result of recruitment to the plasma membrane. Science 264: 1463-1467, 1994.

29. Roberts PJ and Der CJ: Targeting the Raf-MEK-ERK mitogenactivated protein kinase cascade for the treatment of cancer. Oncogene 26: 3291-3310, 2007.

30. Chang F, Steelman LS, Shelton JG, Lee JT, Navolanic PM, Blalock WL, Franklin R and McCubrey JA: Regulation of cell cycle progression and apoptosis by the Ras/Raf/MEK/ERK pathway (Review). Int J Oncol 22: 469-480, 2003.

31. Hans F and Dimitrov S: Histone H3 phosphorylation and cell division. Oncogene 20: 3021-3027, 2001.

32. Chadee DN, Hendzel MJ, Tylipski CP, Allis CD, Bazett-Jones DP Wright JA and Davie JR: Increased Ser-10 phosphorylation of histone $\mathrm{H} 3$ in mitogen-stimulated and oncogene-transformed mouse fibroblasts. J Biol Chem 274: 24914-24920, 1999.

33. Agarwal ML, Agarwal A, Taylor WR and Stark GR: 553 controls both the G2/M and the G1 cell cycle checkpoints and mediates reversible growth arrest in human fibroblasts. Proc Natl Acad Sci USA 92: 8493-8497, 1995.

34. Ciccarelli C, Marampon F, Scoglio A, Mauro A, Giacinti C, De Cesaris P and Zani BM: p21 ${ }^{\mathrm{WAF} 1}$ expression induced by MEK/ ERK pathway activation or inhibition correlates with growth arrest, myogenic differentiation and onco-phenotype reversal in rhabdomyosarcoma cells. Mol Cancer 4: 41-41, 2005.

35. Harper JW, Adami GR, Wei N, Keyomarsi K and Elledge SJ: The p21 Cdk-interacting protein Cip1 is a potent inhibitor of G1 cyclin-dependent kinases. Cell 75: 805-816, 1993.

36. Vermeulen K, Van Bockstaele DR and Berneman ZN: The cell cycle: A review of regulation, deregulation and therapeutic targets in cancer. Cell Prolif 36: 131-149, 2003. 